\title{
Enhanced physical therapy for arm function after stroke: a one year follow up study
}

\author{
Alan Sunderland, Debbie Fletcher, Lesley Bradley, Debbie Tinson, \\ Richard Langton Hewer, Derick T Wade
}

\begin{abstract}
Ninety seven patients with stroke who had participated in a randomised trial of conventional physical therapy $v$ an enhanced therapy for arm function were followed up at one year. Despite the emphasis of the enhanced therapy approach on continued use of the arm in everyday life, the advantage seen for some patients with enhanced therapy at six months after stroke had diminished to a non-significant trend by one year. This was due to some late improvement in the conventional therapy group whereas the enhanced therapy group remained static or fell back slightly. It is recommended that trials should be conducted comparing very intensive therapy for the arm with controls without treatment. This would provide a model of the effects of therapy on intrinsic neural recovery that would be relevant to all areas of neurological rehabilitation.
\end{abstract}

(F Neurol Neurosurg Psychiatry 1994;57:856-858)

In a previous paper ${ }^{1}$ we reported that compared with orthodox physiotherapy an enhanced physical therapy regime produced gains in recovery of arm function over the first six months after stroke. By contrast with conventional therapy, the enhanced therapy included more than double the amount of physiotherapy for the arm and also various techniques aimed at relearning of motor skills and encouraging use of the affected arm in everyday life. The benefits of enhanced therapy seemed greatest for patients with a mild initial impairment of arm function and were statistically significant but insufficient to lead to clinically significant gains on the untimed practical tasks of the Frenchay arm test. $^{2}$

One hypothesis was that the greater active involvement of patients with enhanced therapy in their own therapy programme and the emphasis on arm use in everyday life would lead to gains that would be better sustained after discharge from therapy than seen under conventional therapy. If this were the case then a clinically significant difference between conventional therapy and enhanced therapy groups might emerge at late follow up. A one year follow up of all patients in the initial study was therefore attempted.

\section{Patients and methods}

PATIENTS

Ninety seven (73\%) of the 132 patients who had been in the treatment trial were reassessed close to one year after stroke (mean time since stroke 52 (SD4) weeks; range 39-64). Death or further major strokes were the most common reasons for drop out. There were 48 patients who had received enhanced therapy (22 women, 26 men; 21 left sided weakness, 27 right; mean age 66 (SD11) years), and 49 who had received conventional therapy (27 women, 22 men; 23 left sided weakness, 26 right; mean age 69 (SD9) years). As at the earlier assessments, the groups were similar at one year in their functional independence as assessed by the Barthel activities of daily living scale (enhanced therapy group mean 17 (SD3); conventional therapy group mean 17 (SD3)).

\section{ASSESSMENT METHODS}

The tests of arm function were the same as reported previously. ${ }^{1-3}$ These were (a) Range and strength of active movement (extended motricity index and motor club assessments) (b) motor skills (nine-hole peg test and Frenchay arm test). Also, there was clinical assessment of resistance and pain on passive movement of the arm.

\section{Results}

EFFECT OF THERAPY ON AMOUNT OF ARM RECOVERY

The table and figure confirm that up to six months, patients under the enhanced therapy regime who had a mild initial impairment showed better recovery than similar patients with conventional therapy. This emerged on those tests that are most sensitive to change (extended motricity index and nine-hole peg test). For patients with a severe initial impairment, the figure shows that by chance those allocated to enhanced therapy had on average a slightly more profound initial impairment of arm function, but the recovery curves are essentially parallel for enhanced therapy and conventional therapy subgroups.

There was little change between six 
Mean amount of change between assessment points on tests of arm function

\begin{tabular}{|c|c|c|c|c|}
\hline & \multicolumn{2}{|c|}{ Severe† subgroup } & \multicolumn{2}{|c|}{ Mild subgroup } \\
\hline & $\begin{array}{l}C T \\
(n=24)\end{array}$ & $\begin{array}{l}E T \\
(n=29)\end{array}$ & $\begin{array}{l}C T \\
(n=25)\end{array}$ & $\begin{array}{l}E T \\
(n=19)\end{array}$ \\
\hline \multicolumn{5}{|l|}{ Extended motricity index: } \\
\hline Initial -6 months & 26 & 25 & 11 & $25^{\star \star}$ \\
\hline 6 months-1 year & 3 & 4 & 8 & -1 \\
\hline \multicolumn{5}{|l|}{ Motor club assessment: } \\
\hline Initial -6 months & $3 \cdot 0$ & $2 \cdot 9$ & $1 \cdot 3$ & $1 \cdot 8$ \\
\hline 6 months -1 year & $0 \cdot 2$ & $-0 \cdot 1$ & $0 \cdot 7^{\star}$ & $0 \cdot 2$ \\
\hline \multicolumn{5}{|l|}{9 Hole peg test (pegs/s): } \\
\hline Initial- 6 months & $0 \cdot 11$ & 0.07 & 0.32 & $0 \cdot 41^{\star}$ \\
\hline 6 months -1 year & 0 & 0 & 0.02 & \\
\hline \multicolumn{5}{|l|}{ Frenchay arm test: } \\
\hline Initial- 6 months & $1 \cdot 7$ & $1 \cdot 3$ & $1 \cdot 6$ & $1 \cdot 7$ \\
\hline 6 months -1 year & 0 & 0 & 0.1 & $0 \cdot 1$ \\
\hline
\end{tabular}

${ }^{\star} \mathrm{p}<0.05 ;{ }^{\star \star} \mathrm{p}<0.01$. CT: conventional therapy group; ET: enhanced therapy group + Patients were classified as severe if they were unable to pass any subtest of the Frenchay arm test when assessed within three weeks of stroke. Differences within subgroups were tested with the Mann-Whitney U test.

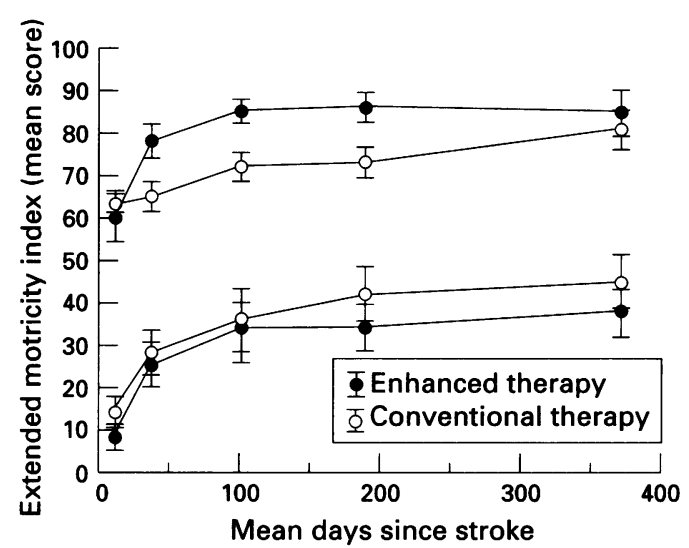

Recovery curves for patients receiving conventional therapy and enhanced therapy. The top curves are for patients initially classified as mildly impaired and the bottom curves for the severe subgroup. The bars are SEM.

months and one year. Taking the average for all 102 patients, only the extended motricity index showed a statistically significant increase over this period (mean increase 4; Wilcoxon signed ranks test, $\mathrm{p}<0.01$ ). The table shows that there was a consistent trend within the mild subgroup for patients with enhanced therapy to remain static or decline slightly whereas patients with conventional therapy showed a slight improvement. This trend reached statistical significance on the motor club assessment.

FINAL OUTCOME

At one year, there were no statistically significant differences between enhanced therapy and conventional therapy subgroups on any measure. On the Frenchay arm test the median scores were zero for both patients with enhanced therapy and patients with conventional therapy who had a severe initial impairment, and 5 (full marks) for those with enhanced therapy and conventional therapy with a mild initial impairment. On clinical examination, 26 of the patients with enhanced therapy had resistance to passive movement compared with 24 patients with conventional therapy. Pain was reported for 16 patients with enhanced therapy and 14 patients with conventional therapy.

\section{Discussion}

The hypothesis that the patients with enhanced therapy would show better long term outcome was not confirmed. For those patients with an initial mild impairment, the slight advantage seen for the enhanced therapy group at six months had diminished to a non-significant trend by one year. This was due to the conventional therapy group making small late gains in arm function and catching up with the patients with enhanced therapy, who remained static or fell back slightly over the same period.

On a more positive note, the recovery curves for the subgroup of patients who could be followed up at one year showed a pattern entirely consistent with the data for the whole group assessed at six months and reported in our earlier paper. ${ }^{1}$ The consistency of these data gives us confidence that our earlier results were not due to measurement error but that there was a real effect of enhanced therapy on early recovery. It seems that enhanced therapy accelerated recovery to a plateau that was only approached at a much later date by patients with conventional therapy.

This effect, although reliable, was small and did not on average improve everyday movement skills as assessed by the Frenchay arm test. The enhanced regime represented a small change in rehabilitation practice, which was highly constrained by the daily routine in a general hospital, ${ }^{4}$ and ethical considerations prevented us from comparing enhanced therapy with a control group without treatment. We believe that the small effects seen in this study and the lack of evidence of therapy related effects in other studies, ${ }^{5-7}$ provide ethical justification for a much more radical trial in which conservatively managed controls are compared to a group of patients with mild initial impairment who receive a very intensive arm function training programme that combines hospital and home based therapeutic activities. Only by taking such a radical approach can we discover how scarce rehabilitation resources can best be used to the advantage of our patients.

In conclusion, enhanced physical therapy during the first six months after stroke did not lead to gains at one year, but it did cause an early acceleration to a level only approached much later by patients who received conventional therapy. This acceleration, although statistically significant, was not sufficient to have a clinically important effect on the average patient. A more radical treatment trial is needed to discover if this treatment approach has the potential to produce a significantly better return of useful motor skills. The study of recovery of arm function may provide data on the general rules of recovery after stroke, and may indicate whether therapies should continue to focus on promoting the return of lost brain functions or should instead take as their primary aim the teaching of ways to adapt to residual neurological and neuropsychological impairments. 
This work was supported by a grant from the Stroke Association.

1 Sunderland A, Tinson DJ, Bradley EL, Fletcher D, Langton Hewer R, Wade DT. Enhanced physical therapy improves recovery of arm function after stroke. A randomised controlled trial. $f$ Neurol Neurosurg Psychiatry 1992;55:530-5.

2 Sunderland A, Tinson D, Bradley L, Langton Hewer R. Arm function after stroke. An evaluation of grip strength as a measure of recovery and a prognostic indicator. as a measure of recovery and a prognostic

F Neurol Neurosurg Psychiatry 1989;52:1267-72.
3 Heller A, Wade DT, Wood VA, Sunderland A, Langton
Hewer R, Ward E. Arm function after stroke: measurement and recovery over the first three months. $\mathcal{F}$ Neurol Neurosurg Psychiatry 1987;50:714-9.

4 Tinson DJ. How stroke patients spend their days. International Disability Studies 1989;11:45-9.

5 Basmajian JV, Gowland CA, Finlayson AJ, et al. Stroke treatment: comparison of integrated behavioral-physical therapy vs traditional physical therapy programs. Arch Phys Med Rehabil 1987;68:267-72.

6 Dickstein R, Hocherman S, Pillar T, Shaham R. Stroke rehabilitation. Three exercise therapy approaches. Phys Ther 1986;66:1233-8.

7 Logigian MK, Samuels MA, Falconer JF. Clinical exercise trial for stroke patients. Arch Phys Med Rehabil 1983; 64:364-7.

\section{A note on Menière's syndrome}

"He that is giddy thinks the world turns round" Taming of the shrew, $\mathrm{V}, \mathrm{ii}, 20$

Shakespeare and his son-in-law, Dr John Hall, encountered patients with concurrent vertigo and deafness. ${ }^{1}$ Sir William Gowers reported that: "The association of tinnitus aurium and vertigo was noted by Burns in 1809", ${ }^{2}$ long before Menière's description. Martin Luther suspected Satanic inflictions as cause of his disease; ${ }^{3}$ later opinions were of cerebral apoplectiform congestions, or of psychosis.

Menière's contribution was the concept indicating that deafness, tinnitus and vertigo were caused by lesions of the inner ear without pathology of the middle ear, acoustic nerve or brain. Prosper Menière (1799-1862) had attended

"A young lady who, having travelled at night on the outside seat of a diligence while menstruating, caught a cold and suffered complete and sudden deafness." On admission she had "a continual vertigo; the slightest effort of moving produced vomiting". She died five days later. "The only lesion I found was that the semicircular canals were filled with a plastic (plastique) red matter... the material lesion... resides in the semicircular canals."

He continued his observations between 1834 and 1838 , reporting this case in an annotation to his translation of W Kramer's Textbook of otology in 1848. Not until 1861 at the Académie de Medicin de Paris did he describe the complete syndrome, providing details of this case and the postmortem findings of 25 years earlier. It is now considered that Menière's case was not idiopathic, but was caused either by leukaemic haemorrhage or acute purulent labyrinthitis. Controversy waged for many decades about whether or not there was an idiopathic Menière's disease.

Born at Angers on the Loire in 1799, son of a tradesman, Menière graduated in Medicine in Paris in 1926 and was assistant to Baron Dupuytren at the Hôtel Dieu during the civil uprisings of 1830 when 2000 rioters were treated for injuries. While assistant professor, he was asked by the Government to determine if the Duchess of Berry was pregnant. The Duchess was the widow of the murdered Duc de
Berry, son of Charles $\mathrm{X}$, and her own son was therefore in line for accession to the throne. Menière decided she was pregnant but support for accession soon disappeared when it was discovered that the son was fathered by an Italian after a clandestine marriage. No longer a threat, the Duchess was released and went with Menière to Naples.

In 1838, a year after failing in his application to become Professor of Medicine and Hygiene, he was appointed Physician to the Institute for Deaf Mutes. In the same year he married Mme Becquerel: a relative of Anton Becquerel who discovered radioactivity.

Menière's researches were influenced by the experiments on birds of MJP Flouris in 1820, who had distinguished hearing and balance as functions of the inner ear.

In 1862 he died of pneumonia.

An unpublished source that has recently come to light $^{5}$ is a cache of letters from the pen of Menière. They illustrate his professional work as a physician his work with deaf-mute patients and their treatment. These writings allow a glimpse into his philosophical mind and into his glamorous social life. Menière was accomplished not only in medicine, but in literary productions and was a prolific writer, personally acquainted with Honoré de Balzac. The letters of Menière show the luminous mind of this man, remembered for one illness, but whose numerous other achievements are often forgotten.

J M S PEARCE 304 Beverley Road,
Anlaby, Hull HU10 $7 B G$

1 Hall J. Select observations on English bodies (Observ. 11; second century) 2nd edn, London: J Sherly, 1679. Cited in Leading article. $B M \mathcal{F}$ 1972;2:743-4.

2 Burns. Observations on diseases of the heart 1809. Cited by Gowers WR, Diseases of the nervous system, London: Churchill, 1888:725.

3 Feldmann H. [Birth of a nosological entity, as exemplified by Menière's disease.] Die Geburt einer Krankheit, dargestellt am beispiel des Morbus Menière. LaryngoRhino-Otol 1993;72:1-8.

4 Menière P. Gaz Méd Paris 1861, 3 sér., 16:29. See: Atkinson $M$. Menière's original papers; reprinted with an English translation together with commentaries and biographical sketch. Acta Otolaryngol (suppl 162), biograph.

5 Pappas DG, McGuinn MG. Unpublished letters from Pappas DG, McGuinn MG. Unpublished letters from
Prosper Menière: A personal silhouette. Am $f$ Otol 1993;14:318-25. 